\title{
Cordonnier Grade 1 Clinically Documented Infection not Requiring Inpatient Management
}

National Cancer Institute

\section{Source}

National Cancer Institute. Cordonnier Grade 1 Clinically Documented Infection not

Requiring Inpatient Management. NCI Thesaurus. Code C138315.

Any clinically documented infection not requiring inpatient management. 